\title{
An evaluation of peak acceleration amplification coefficients in a CFR dam considering hydrodynamic pressure
}

\author{
M.E. Kartal* \\ İzmir Democracy University, Engineering Faculty, 35140, İzmir, TURKEY
}

\begin{abstract}
The aim of this paper is to present accelerations and peak acceleration amplification coefficients in a concrete faced rockfill (CFR) dam. For this purpose, Torul CFR dam is considered by using finite element method. Hydrodynamic pressure of the reservoir water is considered modeled using the fluid finite elements based on the Lagrangian approach. Deconvolution of surface accelerograms is taken into account in numerical solutions. Geometric, material and connection non-linearity are considered in the finite element analyses. The Drucker-Prager model and the multi-linear kinematic hardening model are used for concrete slab and rockfill, respectively, in the materially non-linear analysis. Non-linear behavior of the rockfill is obtained by the uniaxial stress-strain relation. The stress-strain curve of the rockfill is obtained using the shear modulusshear strain relation produced for the gravels. Different joints in the CFR dam are modeled with both welded and friction contacts. The friction in the joints is provided with contact-target element pairs based on the Coulomb's friction law. The accelerations in the bottom and crest of the dam are compared each other since welded and friction contact in dam-foundation interface. Then peak acceleration amplification coefficients are also obtained compared each other. According to numerical comparisons, when the rockfill behaves materially non-linear, the maximum horizontal accelerations and peak acceleration amplification coefficients decrease in the crest.
\end{abstract}

\section{Keywords}

Concrete faced rockfill (CFR) dam; Friction contact; Hydrodynamic pressure; Non-linear earthquake behavior

Received: 31 March 2018; Accepted: 30 June 2018

ISSN: 2630-5763 (online) @ 2018 Golden Light Publishing ${ }^{\circledR}$ All rights reserved.

\section{Introduction}

Concrete faced rockfill (CFR) dam behavior under seismic excitation is very important and also complex. Because it includes dam-foundationreservoir interaction. CFR dams are exposed to hydrodynamic pressure on face slab. These dams prevent water penetration in the upstream face. Therefore, concrete-faced rockfill dams are known as safe structures under seismic excitations because they do not include porewater development.
Earthquake behavior of CFR dams under ground motion effects was investigated by several researchers [1-5]. One of the most important factor affecting the response of CFR dams is the interface behaviour of interaction surfaces of CFR dams. There are various joints in a CFR dam. Therefore, the dam response clearly depends on the quality of the numerical modelling including joints in these dams. Some researchers focused on the effect of the concrete slab-rockfill interface behavior in CFR dams considering friction and welded contact [5,

\footnotetext{
Corresponding author

E-mail: murat.kartal@idu.edu.tr
} 
6]. The design procedures should be assessed and developed by in-situ measurements and numerical simulations. The accelerations in the crest and acceleration amplification may be evaluated as an important parameter for the seismic response of a CFR dam.

This study comprehensively investigates the horizontal accelerations and peak accelerations amplification coefficients occurred in a CFR dam to deconvolved ground motion. The main of aim this paper is to fill an important gap related to this subject in this area. For this purpose, finite element modelling and analyses were carried out. Infinite boundary conditions were taken into consideration by using viscous dampers in foundation and reservoir water boundaries of the finite element model. The effect of the reservoir water on the upstream face of the dam is modelled by twodimensional fluid finite elements based on the Lagrangian approach. Welded and friction contact are used in the all joints of the interaction surfaces of the dam-reservoir-foundation interaction model. One-dimensional contact elements which uses the Coulomb's law is used to describe friction in the joints. The Drucker-Prager model for concrete slab and the multi-linear kinematic hardening model for rockfill are used to represent materially non-linear behavior. The uniaxial stress-strain relationship of the rockfill is derived from the shear modulusshear strain relationship of the gravels [7].

\section{Dam-reservoir-foundation interaction by the Lagrangian approach}

The formulation of the fluid system based on the Lagrangian approach is presented as follows $[8,9]$. This approach assumes the fluid as linearly compressible, inviscid and irrotational. For a general three-dimensional fluid, pressurevolumetric strain relationships can be written in matrix form as follows

$$
\left\{\begin{array}{c}
P \\
P_{x} \\
P_{y} \\
P_{z}
\end{array}\right\}=\left[\begin{array}{cccc}
C_{11} & 0 & 0 & 0 \\
0 & C_{22} & 0 & 0 \\
0 & 0 & C_{33} & 0 \\
0 & 0 & 0 & C_{44}
\end{array}\right]\left\{\begin{array}{c}
\varepsilon_{v} \\
w_{x} \\
w_{y} \\
w_{z}
\end{array}\right\}
$$

where $P, C_{11}$, and $\varepsilon_{v}$ are the pressures which are equal to mean stresses, the bulk modulus and the volumetric strains of the fluid, respectively. Since irrotational behavior of the fluid is considered like penalty methods $[10,11]$, rotations and constraint parameters are included in the pressure-volumetric strain equation (Eq. (1)) of the fluid. In this equation, $P_{x}, P_{y}$ and $P_{z}$ are the rotational stresses; $C_{22}, C_{33}$ and $C_{44}$ are the constraint parameters and $\mathrm{w}_{\mathrm{x}}, \mathrm{w}_{\mathrm{y}}$ and $\mathrm{w}_{\mathrm{z}}$ are the rotations about the Cartesian axis $x, y$ and $z$.

In this study, the equations of motion of the fluid system are obtained using energy principles. Using the finite element approximation, the total strain energy of the fluid system may be written as

$\pi_{e}=\frac{1}{2} \mathbf{U}_{f}{ }^{T} \mathbf{K}_{f} \mathbf{U}_{f}$

where $\mathbf{U}_{f}$ and $\mathbf{K}_{f}$ are the nodal displacement vector and the stiffness matrix of the fluid system, respectively. $\mathbf{K}_{f}$ is obtained by the sum of the stiffness matrices of the fluid elements as follows

$$
\begin{aligned}
& \mathbf{K}_{f}=\sum \mathbf{K}_{\mathbf{f}}^{\mathrm{e}} \\
& \mathbf{K}_{f}{ }^{e}=\int_{\mathbf{V}} \mathbf{B}_{f}{ }^{e T} \mathbf{C}_{f} \mathbf{B}_{f}{ }^{e} \mathbf{d V}^{e}
\end{aligned}
$$

where $\mathbf{C}_{\mathrm{f}}$ is the elasticity matrix consisting of diagonal terms in Eq. (1). $\mathbf{B}_{f}{ }^{e}$ is the straindisplacement matrix of the fluid element.

An important behavior of fluid systems is the ability to displace without a change in volume. For reservoir and storage tanks, this movement is known as sloshing waves in which the displacement is in the vertical direction. The increase in the potential energy of the system because of the free surface motion can be written as

$\pi_{s}=\frac{1}{2} \mathbf{U}_{s f}{ }^{T} \mathbf{S}_{f} \mathbf{U}_{s f}$

where $\mathbf{U}_{s f}$ and $\mathbf{S}_{\mathrm{f}}$ are the vertical nodal displacement vector and the stiffness matrix of the free surface of the fluid system, respectively. $\mathbf{S} f$ is obtained by the sum of the stiffness matrices of the free surface fluid elements as follows 


$$
\left.\begin{array}{rl}
\mathbf{S}_{f} & =\sum \mathbf{S}_{f}{ }^{e} \\
\mathbf{S}_{f}{ }^{e} & =\rho_{f} \mathbf{g} \int_{\mathbf{A}} \mathbf{h}_{s}{ }^{T} \mathbf{h}_{s} \mathrm{dA}^{e}
\end{array}\right\} \text { (5) }
$$

where $\mathbf{h}_{s}$ is the vector consisting of interpolation functions of the free surface fluid element. $\rho_{\mathrm{f}}$ and $\mathrm{g}$ are the mass density of the fluid and the acceleration due to gravity, respectively. Besides, kinetic energy of the system can be written as

$$
\mathrm{T}=\frac{1}{2} \dot{\mathbf{U}}_{f}^{T} \mathbf{M}_{f} \dot{\mathbf{U}}_{f}
$$

where $\dot{\mathbf{U}}_{f}$ and $\mathbf{M}_{f}$ are the nodal velocity vector and the mass matrix of the fluid system, respectively. $\mathbf{M}_{f}$ is also obtained by the sum of the mass matrices of the fluid elements as follows

$$
\left.\begin{array}{rl}
\mathbf{M}_{f} & =\sum \mathbf{M}_{f}{ }^{e} \\
\mathbf{M}_{f}{ }^{e} & =\rho_{f} \int_{\mathbf{V}} \mathbf{H}^{T} \mathbf{H d V}^{e}
\end{array}\right\}
$$

where $\mathbf{H}$ is the matrix consisting of interpolation functions of the fluid element. If (Eq. (2), (4) and (6)) are combined using the Lagrange's equation [12]; the following set of equations is obtained.

$$
\mathbf{M}_{f} \ddot{\mathbf{Y}}_{f}+\mathbf{K}_{f}^{*} \mathbf{Y}_{f}=\mathbf{P}_{f}
$$

where $\mathbf{K}_{f}^{*}, \ddot{\mathbf{U}}_{f}, \mathbf{U}_{f}$ and $\mathbf{R}_{f}$ are the system stiffness matrix including the free surface stiffness, the nodal acceleration and displacement vectors and timevarying nodal force vector for the fluid system, respectively. In the formation of the fluid element matrices, reduced integration orders are used [8].

The equations of motion of the fluid system, (Eq. (8)), have a similar form with those of the structure system. To obtain the coupled equations of the fluid-structure system, the determination of the interface condition is required. Since the fluid is assumed to be inviscid, only the displacement in the normal direction to the interface is continuous at the interface of the system. Assuming that the structure has the positive face and the fluid has the negative face, the boundary condition at the fluidstructure interface is

$$
\mathbf{U}^{-}{ }_{n}=\mathbf{U}^{+}{ }_{n}
$$

where $U_{n}$ is the normal component of the interface displacement [13]. Using the interface condition, the equation of motion of the coupled system to ground motion including damping effects are given by

$$
\mathbf{M}_{c} \ddot{\mathbf{U}}_{c}+\mathbf{C}_{c} \dot{\mathbf{U}}_{c}+\mathbf{K}_{c} \mathbf{U}_{c}=\mathbf{R}_{c}
$$

in which $\mathrm{M}_{\mathrm{c}}, \mathrm{C}_{\mathrm{c}}$, and $\mathrm{K}_{\mathrm{c}}$ are the mass, damping and stiffness matrices for the coupled system, respectively. $\mathbf{U}_{c}, \dot{\mathbf{U}}_{f}, \ddot{\mathbf{U}}_{c}$ and $\mathbf{R}_{c}$ are the vectors of the displacements, velocities, accelerations and external loads of the coupled system, respectively.

\section{Numerical model of a CFR Dam}

\subsection{Torul dam}

The Torul CFR Dam is located on the Harsit River, approximately $14 \mathrm{~km}$ northwest of Torul, Gumushane (Fig. 1). General Directorate of State Hydraulic Works completed the construction of this dam in 2007 [14]. The main goal of the reservoir is power generation. The volume of the dam body is $4.6 \times 106 \mathrm{~m}^{3}$ and the water area of the reservoir at the normal water level is $3.62 \mathrm{~km}^{2}$. The annual total power generation capacity is $322.28 \mathrm{GW}$. The length of the dam crest is $320 \mathrm{~m}$, the width of the dam crest is $12 \mathrm{~m}$, and the maximum height and base width of the dam crest are $142 \mathrm{~m}$ and $420 \mathrm{~m}$, respectively. The maximum water level is $137.5 \mathrm{~m}$. The thickness of the concrete slab is $0.3 \mathrm{~m}$ at the crest level and $0.7 \mathrm{~m}$ at the foundation level. The largest cross section and the dimensions of the dam are shown in Fig. 2. 


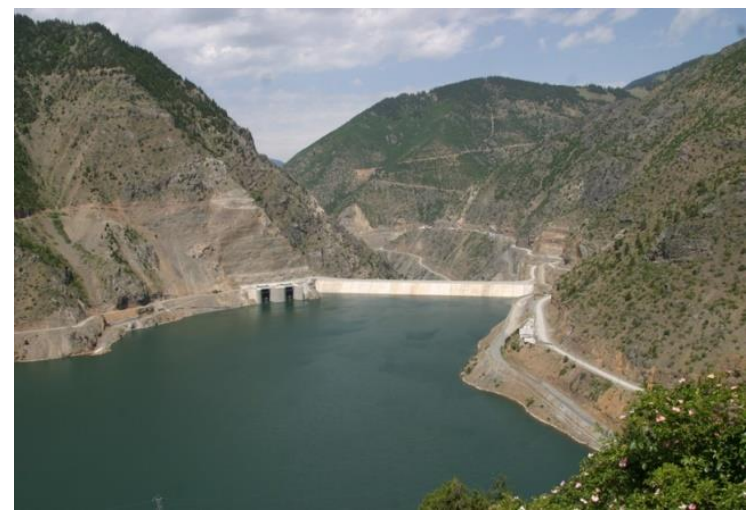

a) Upstream face

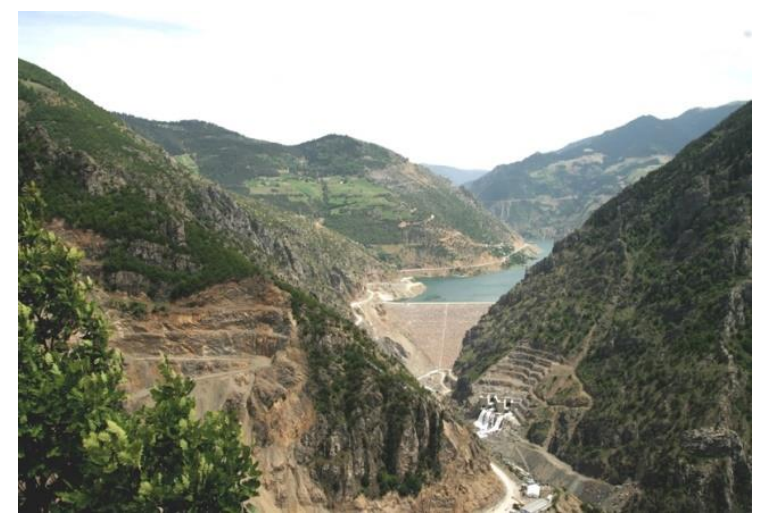

b) Downstream face

Fig. 1. The view of Torul CFR Dam [14]

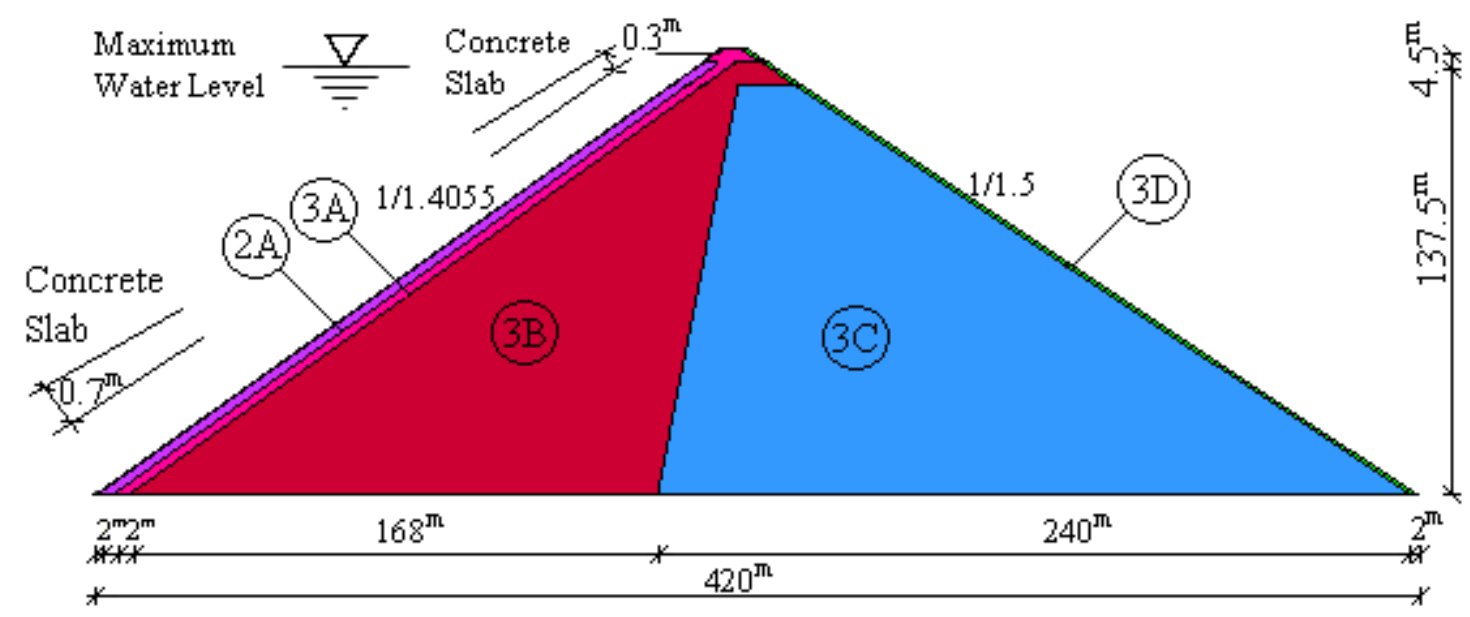

Fig. 2. The largest cross section and the dimensions of the Torul CFR dam (DSI, 2017)

\subsection{Material properties of Torul dam}

The Torul dam body consists of a concrete face slab, transition zones (2A, $3 \mathrm{~A})$, rockfill zones (3B, $3 C)$ and riprap (3D), respectively, from upstream to downstream. These zones are arranged from thin granules to thick particles in the upstreamdownstream direction. Spilite (below), limestone (middle) and volcanic tufa (upper) exist in the foundation soil. The material properties of the dam and foundation soil used in linear and non-linear analysis are given in Table 1 . This study considers the Young's modulus of $3 \mathrm{C}$ zone as $200 \mathrm{MPa}$ [15] because the rockfill is well graded, well compacted and constituted of materials with high compression modulus. The material properties of rockfill zones are chosen considering that elastic constant increases with maximum particle size for alluvial material while it decreases with maximum particle size for quarried material [16]. The cohesion and the angle of internal friction of the concrete are assumed to be $2.50 \mathrm{MPa}$ and $30^{\circ}$, respectively. In addition, the concrete has a tensile strength of $1.6 \mathrm{MPa}$ and compression strength of 20MPa [17]. The bulk modulus and mass density of the reservoir water are $2.07 \times 10^{3} \mathrm{MPa}$ and $1000 \mathrm{~kg} / \mathrm{m}^{3}$, respectively. 
$\underline{\text { Table 1. Material properties of Torul CFR dam }}$

\begin{tabular}{lcccc}
\hline \multirow{2}{*}{ Material } & * $\mathrm{D}_{\max }$ & \multicolumn{3}{c}{ Material Properties } \\
\cline { 4 - 5 } & $(\mathrm{mm})$ & $\begin{array}{c}\text { Young's Modulus } \\
\left(10^{7} \mathrm{kN} / \mathrm{m}^{2}\right)\end{array}$ & Poisson's Ratio & $\begin{array}{c}\text { Mass Density } \\
\left(\mathrm{kg} / \mathrm{m}^{3}\right)\end{array}$ \\
\hline Concrete & - & 2.800 & 0.20 & 2395.5 \\
2A (sifted rock or alluvium) & 150 & 0.040 & 0.36 & 1880.0 \\
3A (selected rock) & 300 & 0.030 & 0.36 & 1870.0 \\
3B (quarry rock) & 600 & 0.025 & 0.32 & 1850.0 \\
3C (quarry rock) & 800 & 0.020 & 0.32 & 1850.0 \\
3D (selected rock) & 1000 & 0.018 & 0.26 & 1800.0 \\
Foundation Soil (volcanic tufa) & - & 1.036 & 0.17 & 2732.9 \\
Foundation Soil (limestone) & - & 1.206 & 0.18 & 2834.8 \\
Foundation Soil (Spilite) & - & 1.387 & 0.18 & 2834.8 \\
\hline *Maximum particle size & & & & \\
\hline
\end{tabular}

\subsection{Finite element model of Torul dam}

The two-dimensional finite element model the selected CFR dam is shown in Fig. 3. That includes dam-foundation-reservoir interaction. This model also includes plinth. The solid elements used in the finite element model have four nodes and $2 \times 2$ integration points; the fluid elements have four nodes and $1 \times 1$ integration point. The finite element model contains various joints for the connections of different sections of the dam. Totally 72 contact- target element pairs are defined in the joints of the dam for friction.

The dam crest is $12 \mathrm{~m}$ wide, the maximum height of the dam and maximum water level are $142 \mathrm{~m}$ and $137.5 \mathrm{~m}$, respectively, in the finite element model. The length for both the reservoir water and foundation soil in the upstream direction is considered as three times of the dam height. In addition, the total height of the soil layers and soil length in the downstream direction are taken into account as the dam height.

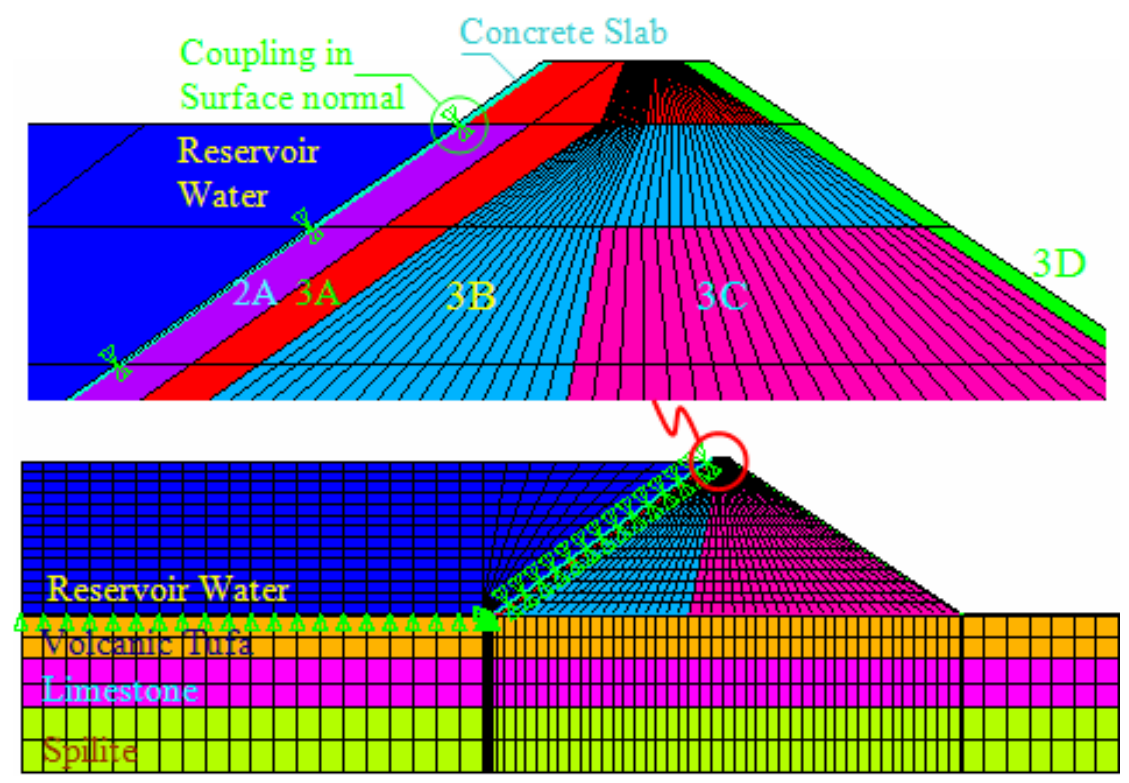

Fig. 3. Two-dimensional finite element model of Torul Dam including impounded water 


\subsection{Structural connections in a CFR dam}

There are various joints in a CFR dam. The connections in these joints are generally modeled considering welded and friction contact. Welded contact defines common nodes in the contact interface. Therefore, stress or displacement transmission is not possible in this interface, because the same displacement and common stress components in the related node of adjacent elements are obtained (Fig. 4). However, interface or contact elements are required for friction contact (Fig. 4). Interface elements, which are four or six noded finite elements for plane systems, provide friction behavior by defined transverse shear stiffness. In the other case, two or three noded contact element pairs define friction. In this study, two noded surface-to-surface contact and target elements are used. In the course of using this element, if contact occurs, sliding appears depending on the maximum shear stress allowed and friction coefficient.
If the material properties of the adjacent media are different, the connection in their interface should be formed with different nodes. It can be said that for a CFR dam, concrete slab-rockfill, rockfill-foundation, concrete slab-plinth and plinthfoundation interfaces can be regarded. Therefore, friction in these interfaces can provide more realistic results. This study considers Coulomb's friction law in these interfaces.

Two contacting surfaces can bear shear stress up to a certain extent across their interfaces before sliding in the Coulomb's friction law. This is named as "stick" case. Coulomb's friction model is defined with ' $\tau$ ' equivalent shear stress in which sliding begins as a part of ' $p$ ' contact pressure. This stress is

$$
\tau_{\lim }=\mu \mathrm{p}+\mathrm{c}
$$
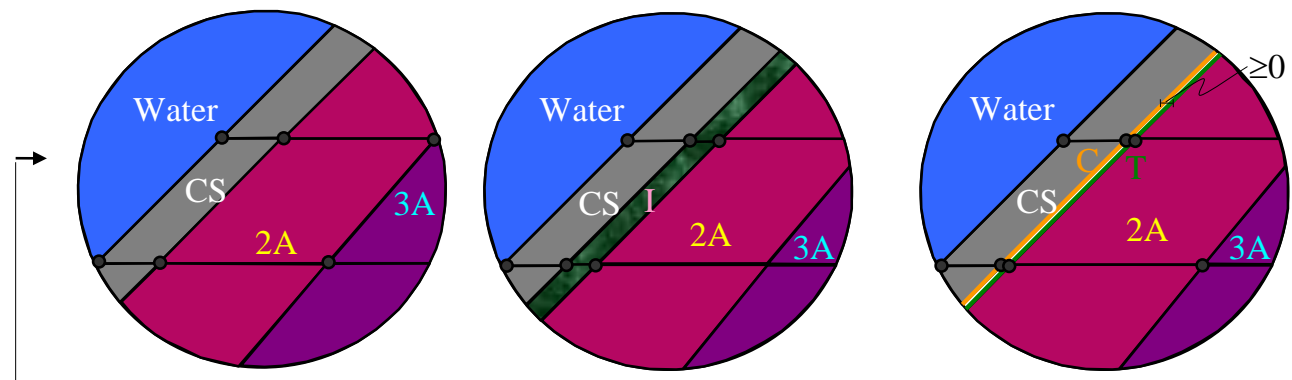

1. Joint with interface elements. 2. Joint with contact elements.

a) Model including welded contact.

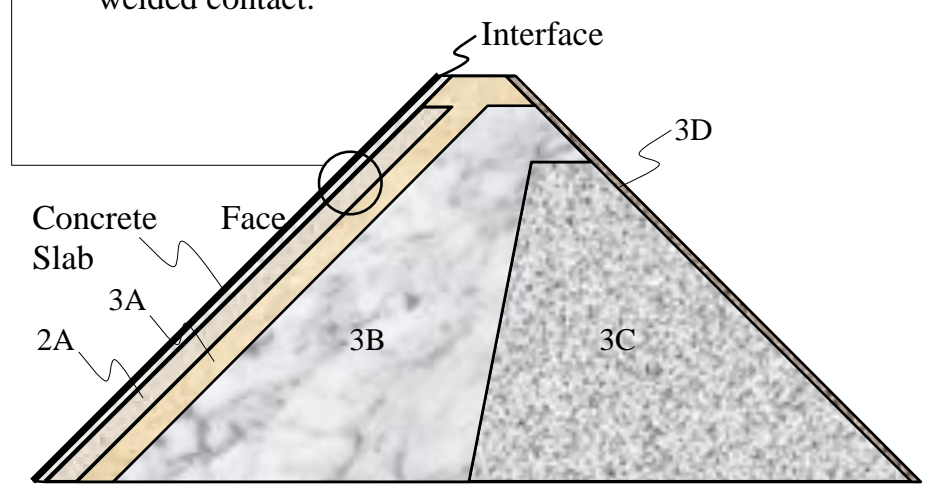

CS: Concrete slab

2A: 2A Transition zone 3A: 3A Transition zone 3B: 3B Rockfill Zone 3C: 3C Rockfill Zone 3D: Riprap

I: Interface Element C: Contact Element $\mathrm{T}$ : Target Element

Fig. 4. Schematic representation of connection types in concrete slab-rockfill interface 
where, $\tau_{\text {lim }}$ is limit shear stress, ' $\mu$ ' is friction coefficient and ' $c$ ' is contact cohesion [18]. Once equivalent shear stress exceeds $\tau_{\text {lim }}$, the contact and target surfaces move relatively in respect of each other. This is named as "sliding". Friction coefficient of ' 0 ' refers the frictionless contact problems. However, friction coefficient is ' 1 ' for bonded surfaces. Maximum shear stress can be calculated using empirical sources. In addition, this stress can also approach $\sigma_{\mathrm{y}} / \sqrt{3}$ where $\sigma_{\mathrm{y}}$ is yield stress. The other term, which is cohesion, has stress unit as shear stress and provides sliding resistance even with zero normal pressure.

\subsection{Non-linear behavior of CFR Dams}

Permanent deformations are observed in the earthfill dams under strong ground motions. This refers that the response of the earthfill dams are actually not linear. Therefore, beyond the linear response of those should be taken into consideration in the numerical analysis. Non-linear response of rockfill and foundation rock is determined by the multi-linear kinematic hardening model. In this method, uniaxial stress-strain curve of the non-linear material is required. This curve can be determined by shear modulus-shear strain relationship for rock and rockfill materials. Rollins et al. [7] produced the best-fit hyperbolic curve defining G/Gmax versus cyclic shear strain relationship for gravelly soils based on testing by 15 investigators (Fig. 5). This study considers the best curve produced by Rollins et al. (7) for rockfill. In addition, shear modulus-shear strain relation for rock soils obtained from experimental studies by Schnabel et al. [19] is used for rock foundation (Fig. 6). The uni-axial stress-strain curves for rockfill and foundation soil are determined by using these curves as shown in Figs. 7 and 8. Besides, nonlinear response of the concrete slab is determined according to the Drucker-Prager material model.

\subsection{Concrete slab thickness}

One of the basic problems for CFR dams is the concrete slab thickness. There is an aspect that a constant thickness of $30 \mathrm{~cm}$ for concrete slab is sufficient. However, the minimum allowed thickness is $30 \mathrm{~cm}$ for concrete slabs. But, how the reduced thickness of the concrete slab affects the performance of a CFR dam subjected to earthquake is a matter of debate.

There are various thickness functions developed for concrete slab depending on dam height (HD). Qian [20] compiled several thickness functions for concrete slab on CFR dams constructed in China. Qian [20] gives some selected functions for concrete slab considered. Bottom thickness is obtained as $72.6 \mathrm{~cm}$ in Table 2 in line 3, but this is fairly near the constructed bottom thickness of the concrete slab of Torul Dam. Therefore, the current thickness of $70 \mathrm{~cm}$ is used in the numerical models.

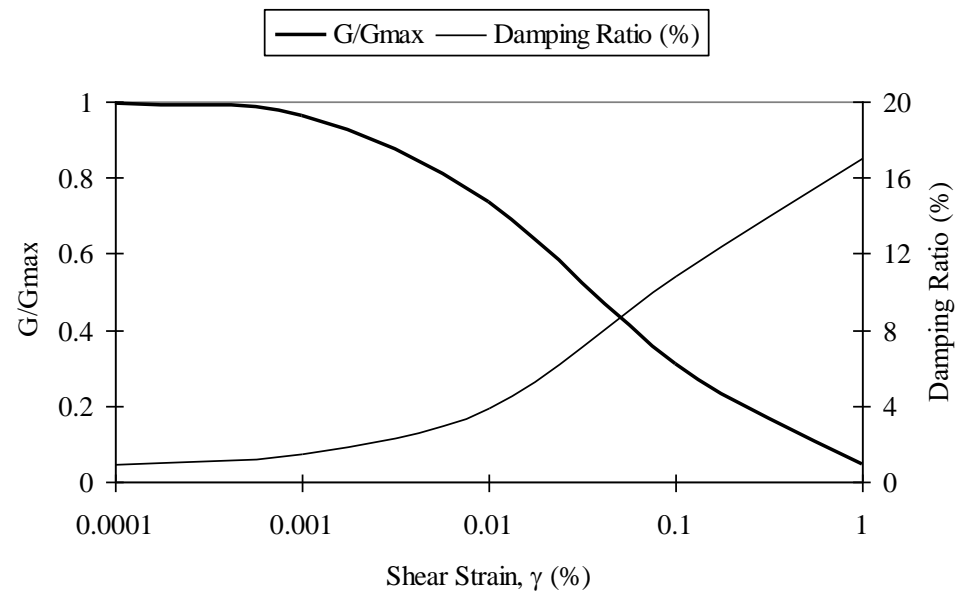

Fig. 5. Normalized shear modulus-shear strain and damping ratio relationships for gravels [7] 


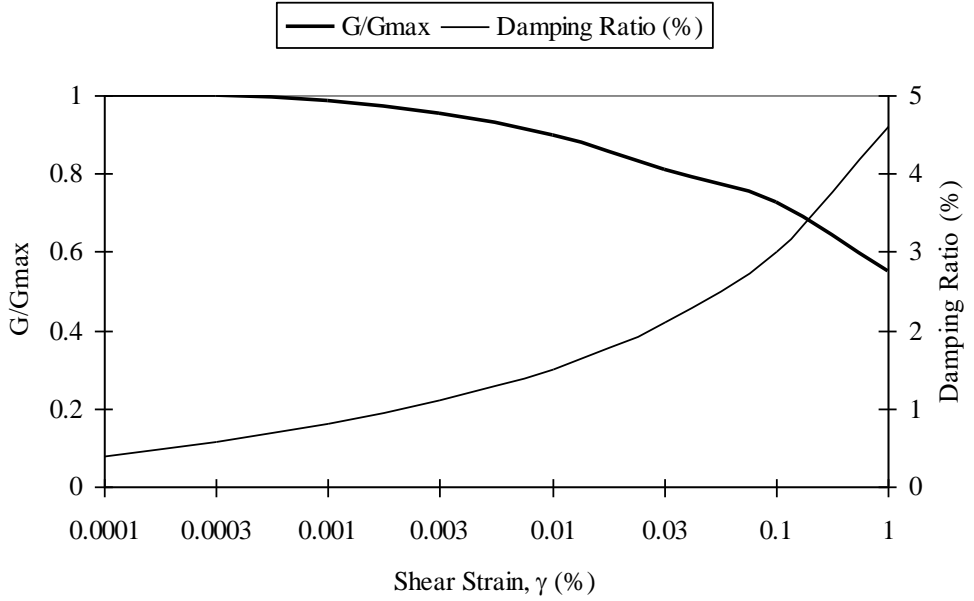

Fig. 6. Normalized shear modulus-shear strain and damping ratio relationships for rocks (Schnabel et al., 1972)

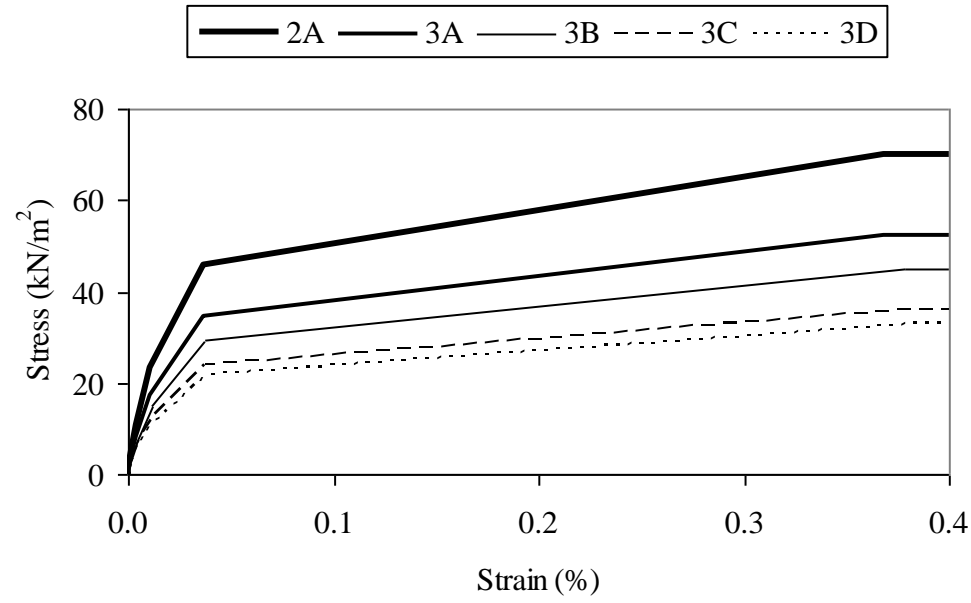

Fig. 7. The uniaxial stress-strain relationship for rockfill

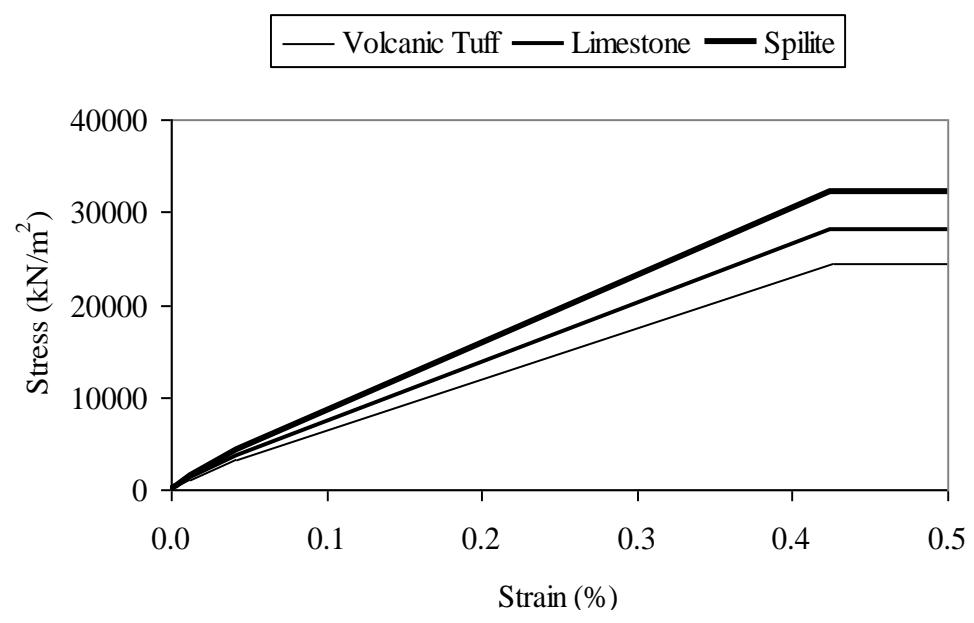

Fig. 8. The uniaxial stress-strain relationship for foundation rock 


\subsection{Analysis cases}

In this study, numerical solutions are performed according to four analysis cases which contain geometrically and materially non-linear analyses as given in Table 3. The aim of these cases is to obviously reveal the effect of the materially nonlinear behavior of the rockfill and concrete slab on the earthquake response of the dam.

\section{Deconvolved ground motion model}

\subsection{The deconvolved-base rock input model}

Free-field surface motions recorded during earthquakes reflect to the characteristics of underlying soil layers at the recording site [21, 22]. Real ground response problems usually involve soil deposits with layers of different stiffness and damping characteristics with boundaries at which elastic wave energy will be reflected and/or transmitted [22]. The theory considers the responses associated with vertical propagation of shear waves through the linear viscoelastic system. A soil deposit consisting of $\mathrm{n}$ horizontal layers where the $\mathrm{n}^{\text {th }}$ layer is bedrock is taken into account in Fig. 9. Each layer is homogeneous and isotropic.

Table 2. Various thickness functions for concrete slab of the CFR dams in China (Qian, 2005)

\begin{tabular}{cccc}
\hline \multirow{2}{*}{$\begin{array}{c}\text { Thickness functions } \\
\text { for concrete slab }\end{array}$} & \multicolumn{2}{c}{$\begin{array}{c}\text { Concrete slab } \\
\text { thickness }(\mathrm{cm})\end{array}$} & \\
\cline { 2 - 3 } & Crest & Bottom & Dam completed year \\
\hline $\mathrm{T}_{b}=0.3$ & 30.0 & 30.0 & Hengshan-1992, Douyan-1995, Chusong-1999 \\
$\mathrm{T}_{\mathrm{b}}=0.3+0.002 \mathrm{H}_{\mathrm{D}}$ & 30.0 & 58.4 & Baiyun-1998, Da' ao-1999, Tianhuagping-1997 \\
$\mathrm{T}_{\mathrm{b}}=0.3+0.003 \mathrm{H}_{\mathrm{D}}$ & 30.0 & 72.6 & Baixi- 2001, Tankeng-2005, Xiaoshan-1997 \\
$\mathrm{T}_{b}=0.3+0.004 \mathrm{H}_{\mathrm{D}}$ & 30.0 & 86.8 & Gouhou-1989 \\
$\mathrm{T}_{b}=0.3+0.8 \mathrm{~m}$ & 30.0 & 110.0 & Jiangpinghe - (221m) \\
\hline
\end{tabular}

Table 3. Numerical analysis cases

\begin{tabular}{ccccccc}
\hline & \multicolumn{5}{c}{ Response } \\
\cline { 2 - 7 } Cases & \multicolumn{3}{c}{ Geometrically } & \multicolumn{3}{c}{ Materially } \\
\cline { 2 - 7 } & Concrete slab & Rockfill & Soil & Concrete slab & Rockfill & Soil \\
\hline Case 1 & Non-linear & Non-linear & Non-linear & Linear & Linear & Linear \\
Case 2 & Non-linear & Non-linear & Non-linear & Linear & Non-linear & Non-linear \\
Case 3 & Non-linear & Non-linear & Non-linear & Non-linear & Non-linear & Non-linear \\
\hline
\end{tabular}

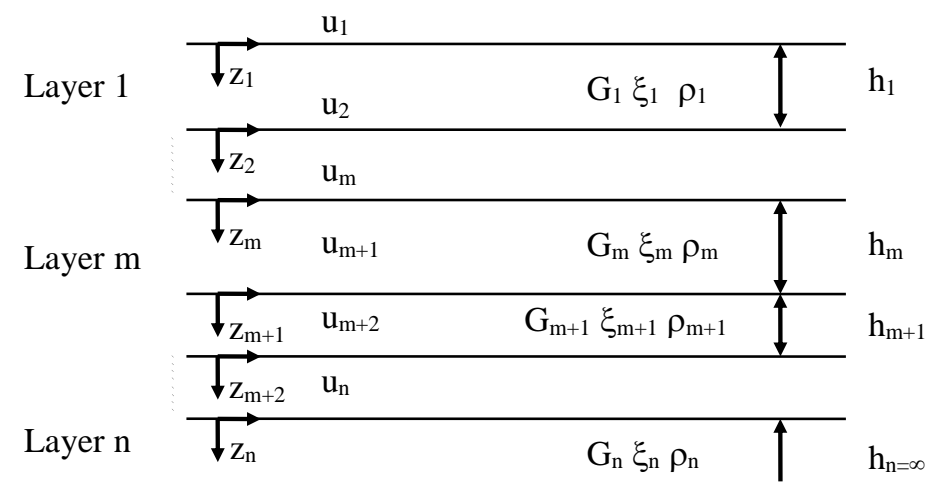

Fig. 9. One-dimensional system 
Vertical propagation of shear waves through the system in Fig. 9 will cause only horizontally displacements. Introducing a local coordinate system $\mathrm{z}$ for each layer, the displacements at the top and bottom of layer $\mathrm{m}$ will be:

$u_{m} z_{m}, t=\left(A_{m} \cdot e^{i k_{m}^{*} z_{m}}+B_{m} \cdot e^{-i k_{m}^{*} z_{m}}\right) e^{i \omega t}$

The shear stresses at the top and bottom of layer $m$ are:

$\tau_{m} \quad z_{m}, t=i k_{m}^{*} G_{m}^{*}\left(A_{m} e^{i k_{m}^{*} z_{m}}-B_{m} e^{-i k_{m}^{*} z_{m}}\right) e^{i \omega t}$

where, values of $z_{m}$ are taken into account as zero and $h_{m}$. The transfer function $F_{i j}(\omega)$ between the displacements at level $\mathrm{i}$ and $\mathrm{j}$ is defined by

$$
F_{i j} \omega=\frac{\left|u_{i}\right|}{\left|u_{j}\right|}=\frac{a_{i}(\omega)+b_{i}(\omega)}{a_{j}(\omega)+b_{j}(\omega)}
$$

where $a_{i}$ and $b_{i}$ are the transfer functions for the case $a_{1}=b_{1}=1$. Eq. (14) describes the amplification of accelerations and velocities. The transfer function, $F_{\mathrm{ij}}(\omega)$, can be found between any two layers in the system. Hence, if the motion is known in any one layer in the system, the motion can be computed in any other layer [19].

\subsection{Ground motion record}

The reliability of the CFR dam is determined to deconvolved ground motion. North-South component of 1992 Erzincan earthquake with peak ground acceleration (pga) of $0.515 \mathrm{~g}$ is used [23]. In this study, earthquake record is deconvolved to base of the rock foundation considering three foundation layers using SHAKE91 [24]. The earthquake record obtained at the ground surface and deconvolved earthquake record are shown in Fig. 10. It is clearly seen that the pga of the deconvolved accelerogram is lower than the freesurface accelerogram.

\section{Numerical results}

One of the most important parameters investigated in CFR dams is the peak acceleration amplification coefficients. They may give important impression about seismic response these dams. Accelerations occurred under strong ground motions increase from the bottom of the dam toward the crest. In this study, the change of the horizontal accelerations obtained at the crest and foundation is presented for different cases and concrete slab thicknesses. The horizontal accelerations are obtained at the middle part of the crest and the intersection part of 3B and $3 \mathrm{C}$ zones at bottom. However, two reciprocal nodes are considered at foundation for the CFR dam including friction contact.

The peak acceleration amplification coefficients of the CFR dam are obtained using the horizontal accelerations $\mathrm{a}_{\text {crest }}, \mathrm{a}_{\text {bottom }}$ and $\mathrm{a}_{\text {foundation }}$ which are the maximum horizontal acceleration at crest, bottom and foundation of the dam. One can obtain peak acceleration amplification coefficients with $\mathrm{a}_{\text {crest }} / \mathrm{a}_{\text {bottom }}$ and $\mathrm{a}_{\text {crest }} / \mathrm{a}_{\text {foundation [25]. Thereby two }}$ different peak acceleration amplification coefficients are calculated in the CFR dam model including friction in the joints.

\subsection{Accelerations in the CFR dam including welded contact in the joints}

The maximum horizontal accelerations and the peak acceleration amplification coefficients obtained in the crest and the bottom of the dam are given in Tables 4-9 for different concrete slab thicknesses. In addition, the change of the horizontal accelerations with time is shown in Figs. 11-16 at these sites.

The change of horizontal accelerations with time fairly resembles each other for different concrete slab thicknesses in empty and full reservoir conditions. However, especially, as the non-linear behavior is considered, the change of the horizontal accelerations with time at crest show an alteration. Such as, the maximum accelerations in empty and full reservoir conditions appear about the third second in Case 1. Those decrease in Cases 2 and 3, whether the horizontal accelerations in the upstream direction increase. 


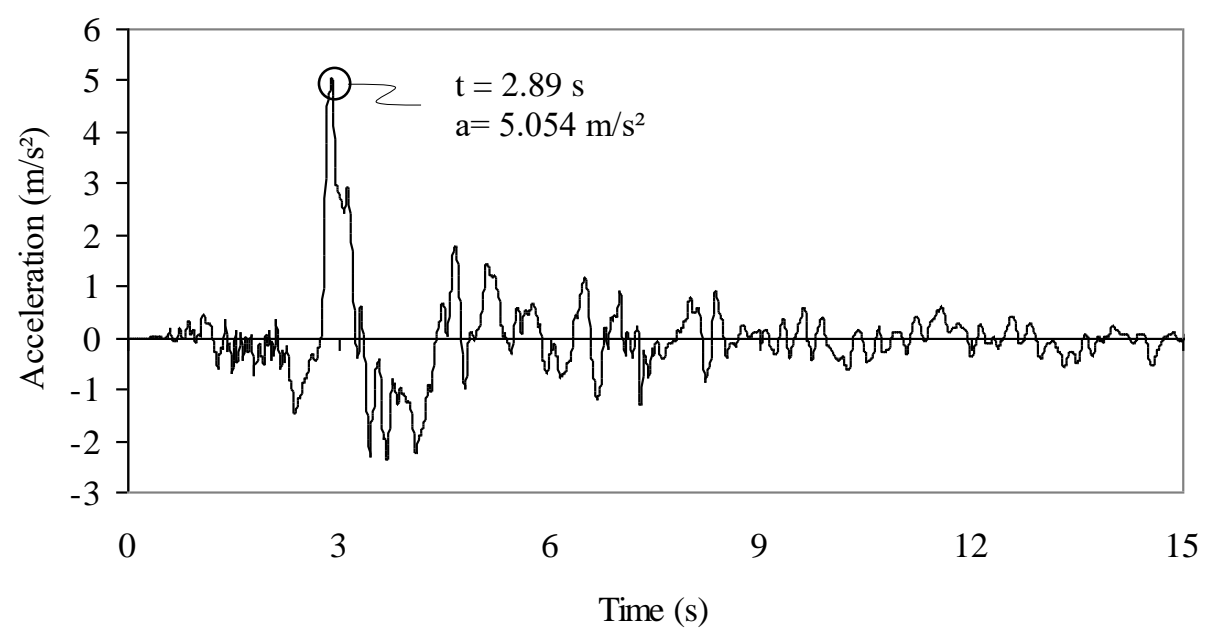

a) The free-surface accelerogram [23]

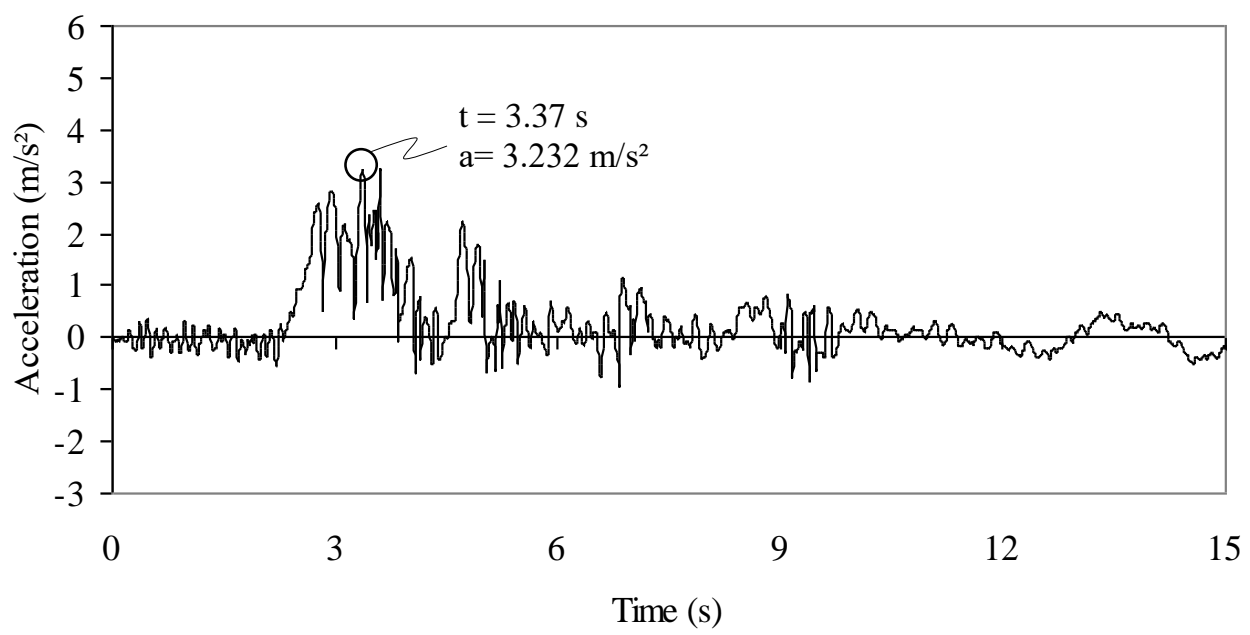

b) The deconvolved accelerogram

Fig. 10. 1992 Erzincan earthquake record

Table 4. The maximum horizontal accelerations and peak acceleration amplification coefficients for welded contact and empty reservoir condition in Case 1

\begin{tabular}{cccccc}
\hline \multirow{2}{*}{$\begin{array}{c}\text { Slab } \\
\text { thickness }\end{array}$} & $30 \mathrm{~cm}$ & $58 \mathrm{~cm}$ & $70 \mathrm{~cm}$ & $87 \mathrm{~cm}$ & $110 \mathrm{~cm}$ \\
\cline { 2 - 6 } & -4.4547 & -4.2676 & -4.2189 & -4.1305 & -3.9925 \\
\multirow{2}{*}{ Crest } & 6.8656 & 6.3540 & 6.1327 & 5.8244 & 5.4209 \\
& -2.2006 & -2.2076 & -2.2097 & -2.2123 & -2.2151 \\
\multirow{2}{*}{ Foundation } & 3.1330 & 3.1388 & 3.1404 & 3.1420 & 3.1432 \\
\hline \multirow{5}{*}{$\mathrm{a}_{\text {crest }} / \mathrm{a}_{\text {foundation }}$} & 2.1914 & 2.0243 & 1.9529 & 1.8537 & 1.7246 \\
\hline
\end{tabular}


Table 5. The maximum horizontal accelerations and peak acceleration amplification coefficients for welded contact and full reservoir condition in Case 1

\begin{tabular}{cccccc}
\hline \multirow{2}{*}{$\begin{array}{c}\text { Slab } \\
\text { thickness }\end{array}$} & $30 \mathrm{~cm}$ & $58 \mathrm{~cm}$ & $70 \mathrm{~cm}$ & $87 \mathrm{~cm}$ & $110 \mathrm{~cm}$ \\
\cline { 2 - 6 } Crest & -4.5760 & -4.4012 & -4.3344 & -4.2873 & -4.1889 \\
& 6.8986 & 6.4651 & 6.2613 & 5.9672 & 5.5701 \\
\multirow{2}{*}{ Foundation } & -2.1971 & -2.2052 & -2.2077 & -2.2107 & -2.2139 \\
& 3.1008 & 3.1079 & 3.1100 & 3.1122 & 3.1142 \\
\hline \multirow{2}{*}{$\mathrm{a}_{\text {crest }} / \mathrm{a}_{\text {foundation }}$} & 2.2248 & 2.0802 & 2.0133 & 1.9174 \\
\hline
\end{tabular}

Table 6. The maximum horizontal accelerations and peak acceleration amplification coefficients for welded contact and empty reservoir condition in Case 2

\begin{tabular}{cccccc}
\hline \multirow{2}{*}{$\begin{array}{c}\text { Slab } \\
\text { thickness }\end{array}$} & $30 \mathrm{~cm}$ & $58 \mathrm{~cm}$ & $70 \mathrm{~cm}$ & $87 \mathrm{~cm}$ & $110 \mathrm{~cm}$ \\
\cline { 2 - 6 } Crest & -5.9791 & -5.9730 & -5.9541 & -5.9102 & -5.8299 \\
& 4.1455 & 4.2062 & 4.2024 & 4.1795 & 4.0958 \\
\multirow{2}{*}{ Foundation } & -2.2557 & -2.2597 & -2.2569 & -2.2543 & -2.2518 \\
& 3.1780 & 3.1783 & 3.1787 & 3.1911 & 3.1998 \\
\hline \multirow{2}{*}{$\mathrm{a}_{\text {crest }} / \mathrm{a}_{\text {foundation }}$} & 1.8814 & 1.8793 & 1.8731 & 1.8521 & 1.8220 \\
\hline
\end{tabular}

Table 7. The maximum horizontal accelerations and peak acceleration amplification coefficients for welded contact and full reservoir condition in Case 2

\begin{tabular}{cccccc}
\hline \multirow{2}{*}{$\begin{array}{c}\text { Slab } \\
\text { thickness }\end{array}$} & $30 \mathrm{~cm}$ & $58 \mathrm{~cm}$ & $70 \mathrm{~cm}$ & $87 \mathrm{~cm}$ & $110 \mathrm{~cm}$ \\
\cline { 2 - 6 } Crest & -5.9575 & -5.9450 & -5.9406 & -5.8696 & -5.3842 \\
& 4.1284 & 4.1230 & 4.1344 & 4.0754 & 4.3753 \\
\multirow{2}{*}{ Foundation } & -2.2493 & -2.2637 & -2.2636 & -2.2610 & -2.2575 \\
& 3.1495 & 3.1483 & 3.1487 & 3.1508 & 3.1671 \\
\hline \multirow{2}{*}{$\mathrm{a}_{\text {crest }} / \mathrm{a}_{\text {foundation }}$} & 1.89158 & 1.88835 & 1.88668 & 1.8629 & 1.7001 \\
\hline
\end{tabular}

Table 8. The maximum horizontal accelerations and peak acceleration amplification coefficients for welded contact and empty reservoir condition in Case 3

\begin{tabular}{cccccc}
\hline \multirow{2}{*}{$\begin{array}{c}\text { Slab } \\
\text { thickness }\end{array}$} & \multicolumn{5}{c}{ Acceleration } \\
\cline { 2 - 6 } & $30 \mathrm{~cm}$ & $58 \mathrm{~cm}$ & $70 \mathrm{~cm}$ & $87 \mathrm{~cm}$ & $110 \mathrm{~cm}$ \\
\hline \multirow{2}{*}{ Crest } & -5.6958 & -5.6135 & -5.6026 & -5.3960 & -5.2444 \\
& 4.5478 & 4.3461 & 4.3178 & 4.0761 & 3.9345 \\
\multirow{2}{*}{ Foundation } & -2.2518 & -2.2425 & -2.2455 & -2.2366 & -2.2209 \\
& 3.2111 & 3.2051 & 3.2031 & 3.1866 & 3.1864 \\
\hline \multirow{2}{*}{$\mathrm{a}_{\text {crest }} / \mathrm{a}_{\text {foundation }}$} & 1.7738 & 1.7514 & \multicolumn{4}{c}{ Acceleration amplification factor } \\
\hline
\end{tabular}


Table 9. The maximum horizontal accelerations and peak acceleration amplification coefficients for welded contact and full reservoir condition in Case 3

\begin{tabular}{cccccc}
\hline \multirow{2}{*}{$\begin{array}{c}\text { Slab } \\
\text { thickness }\end{array}$} & $30 \mathrm{~cm}$ & $58 \mathrm{~cm}$ & $70 \mathrm{~cm}$ & $87 \mathrm{~cm}$ & $110 \mathrm{~cm}$ \\
\cline { 2 - 6 } Crest & -5.5591 & -5.5456 & -5.5152 & -5.3653 & -5.3442 \\
& 4.5591 & 4.5506 & 4.5544 & 4.3644 & 4.3553 \\
\multirow{2}{*}{ Foundation } & -2.2329 & -2.2442 & -2.2492 & -2.2469 & -2.2528 \\
& 3.1694 & 3.1834 & 3.1827 & 3.1759 & 3.1832 \\
\hline \multirow{2}{*}{$\mathrm{a}_{\text {crest }} / \mathrm{a}_{\text {foundation }}$} & 1.7540 & 1.7420 & 1.7329 & 1.6789 \\
\hline
\end{tabular}

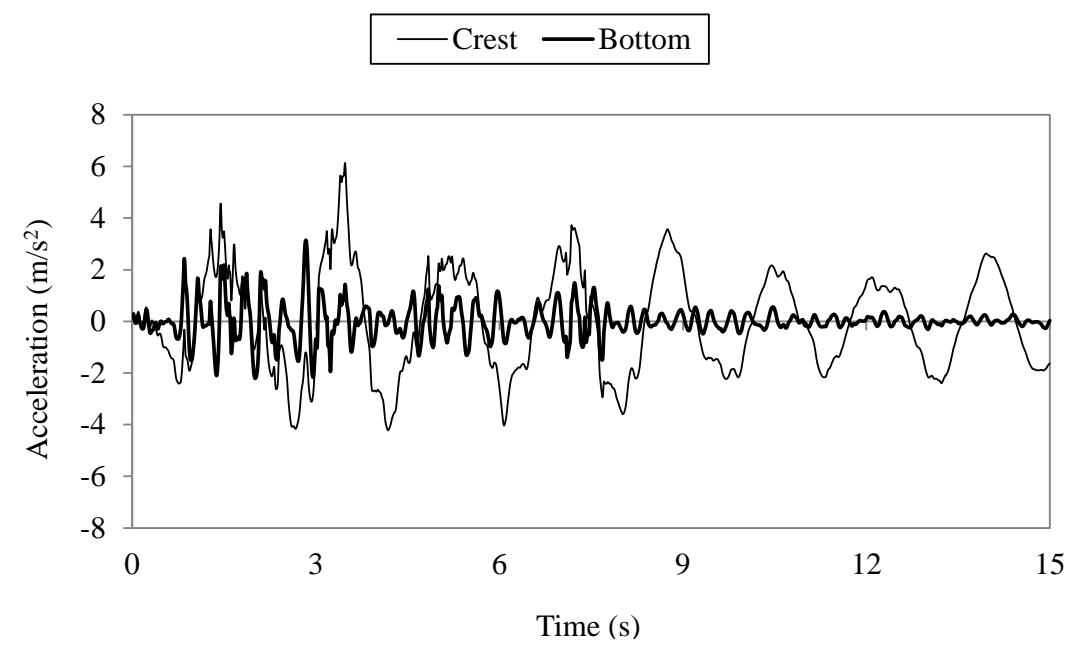

Fig. 11. The horizontal accelerations for welded contact and empty reservoir condition in Case 1

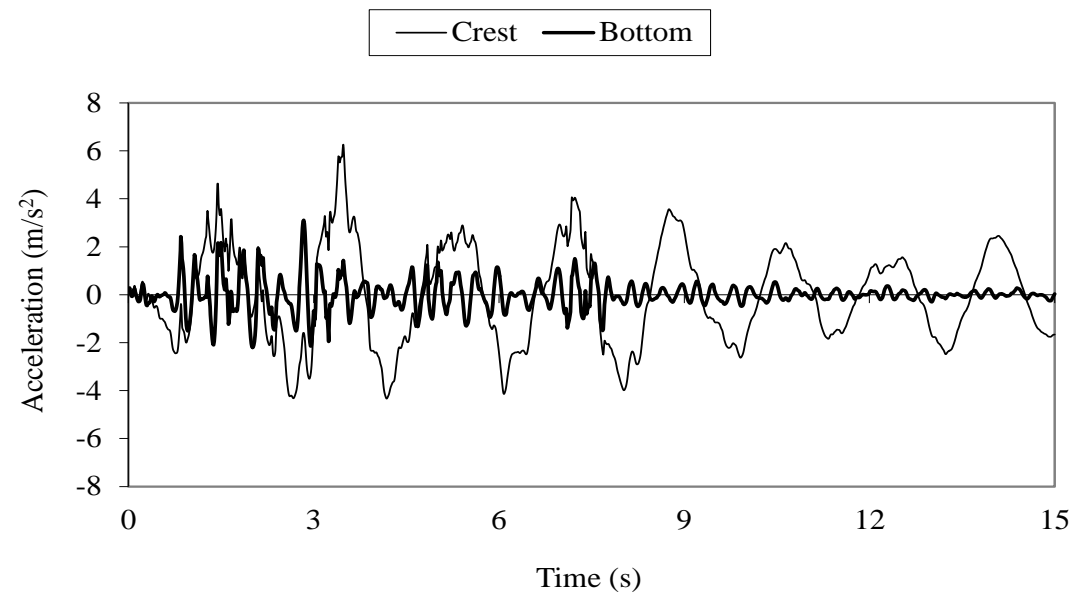

Fig. 12. The horizontal accelerations for welded contact and full reservoir condition in Case 1 


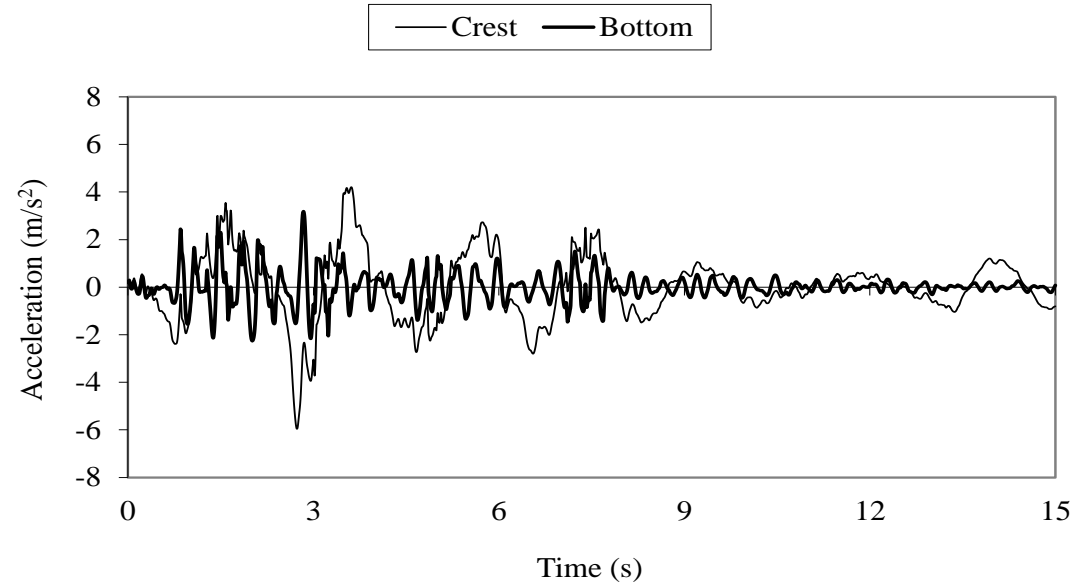

Fig. 13. The horizontal accelerations for welded contact and empty reservoir condition in Case 2

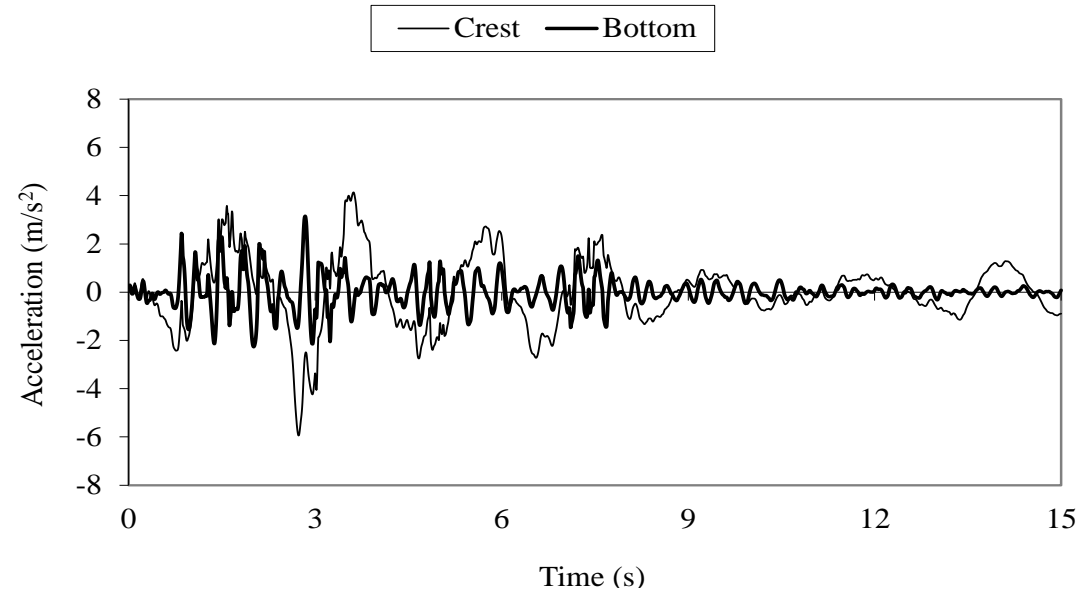

Fig. 14. The horizontal accelerations for welded contact and full reservoir condition in Case 2

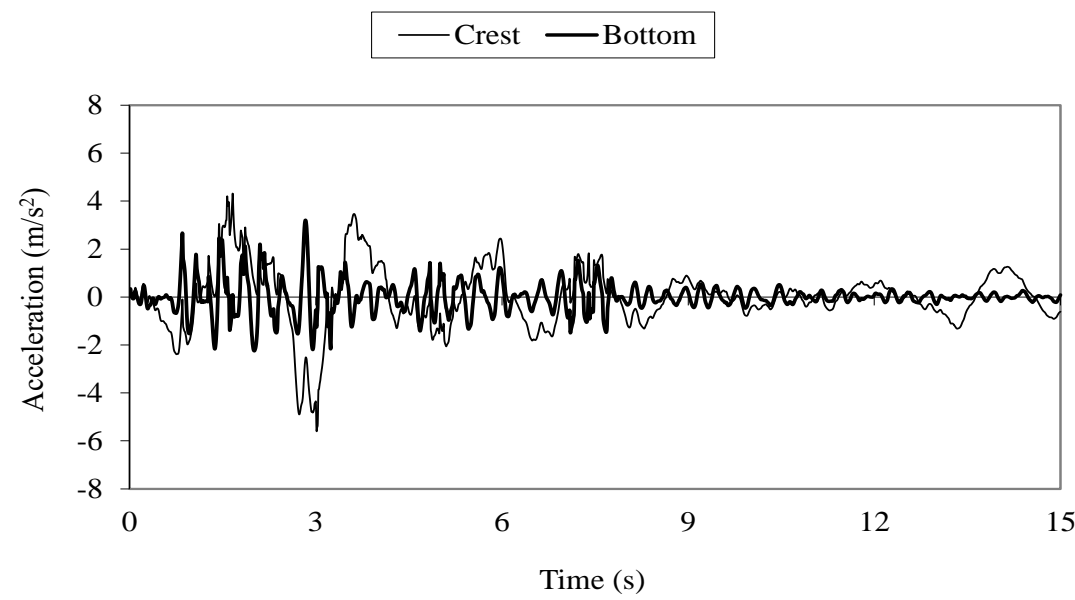

Fig. 15. The horizontal accelerations for welded contact and empty reservoir condition in Case 3 


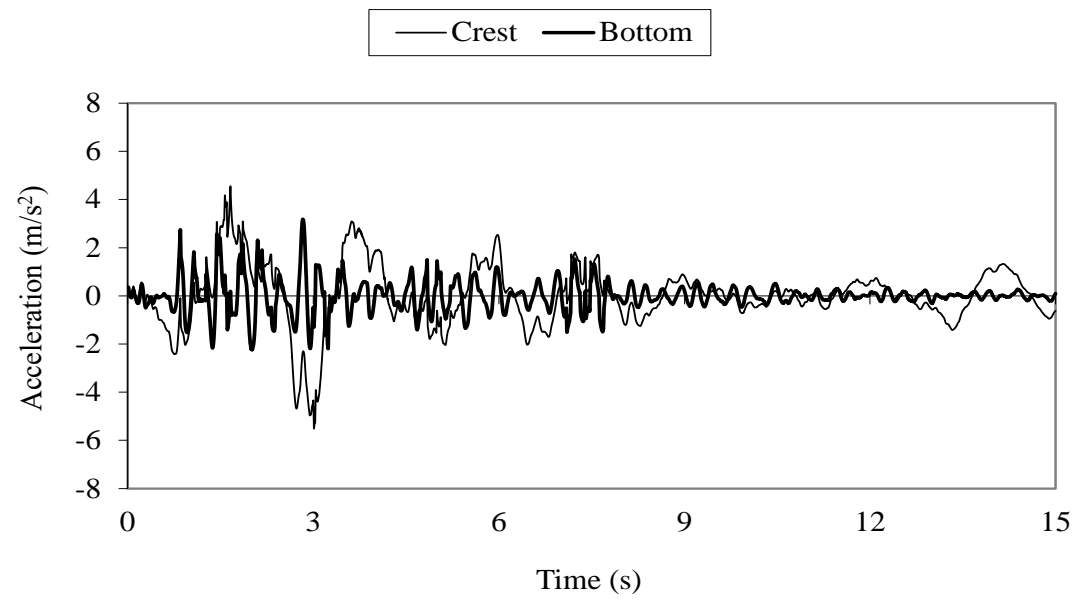

Fig. 16. The horizontal accelerations for welded contact and full reservoir condition in Case 3

The highest acceleration values appear in the upstream direction. But the horizontal accelerations during earthquake are relatively lower than those obtained in Case 1. The horizontal accelerations do not show remarkable change in the bottom of the dam.

The horizontal accelerations and the peak acceleration amplification coefficients increase in the crest depending on those in Case 1 in which the rockfill is materially linear. However, the accelerations do not show a remarkable change in the bottom of the dam. As the concrete slab thickness increases, the accelerations in the crest and peak acceleration amplification coefficients decrease. The maximum horizontal accelerations decrease in the crest in Cases 2 and 3 where the rockfill is non-linear, furthermore peak acceleration amplification coefficients also decrease depending on those. While the accelerations in the crest and peak acceleration amplification coefficients increase by the hydrodynamic pressure in Case 2, those get close to each other in Case 3. The peak acceleration amplification coefficients are obtained lower than 2 in Cases 2 and 3 for each reservoir conditions of the dam including welded contact in the joints. In Case 1, as the face slab thickness decreases, peak acceleration amplification coefficients exceed 2

\subsection{Accelerations in the CFR dam including friction contact in the joints}

The maximum horizontal accelerations and the peak acceleration amplification coefficients obtained in the crest, the bottom of the dam and foundation are given in Tables 10-15 for the dam including friction in the joints according to different concrete slab thicknesses. In addition, the change of the horizontal accelerations at these sites with time is shown in Figs. 17-22.

The hydrodynamic pressure is effective on the horizontal accelerations as the non-linear response of the rockfill. In Case 1, the horizontal accelerations at crest are higher during earthquake in empty reservoir condition as compared those in full reservoir condition. Nevertheless, a somewhat increase appears in the bottom of the dam by the effect of the hydrodynamic pressure about second 3. In Cases 2 and 3, the horizontal accelerations decrease in the crest for empty reservoir condition. Those increases in the bottom of the dam and gives a maximum value in second 3. However, the horizontal accelerations do not show a remarkable change in the foundation in no case for empty reservoir conditions. The maximum horizontal accelerations in the crest appear in second 3 in Cases 3 and 4 for full reservoir condition and also a peak value occurs in bottom of the dam. Besides, the horizontal accelerations occurred in the crest in Cases 2 and 3 during earthquake decrease as compared those occurred in Case 1. According to 
numerical analyses, the hydrodynamics pressure and the non-linear behavior of the rockfill are effective on the accelerations of the bottom of the dam rather than foundation.

Table 10. The maximum horizontal accelerations and peak acceleration amplification coefficients for friction contact and empty reservoir condition in Case 1

\begin{tabular}{cccccc}
\hline \multirow{2}{*}{$\begin{array}{c}\text { Slab } \\
\text { thickness }\end{array}$} & $30 \mathrm{~cm}$ & $58 \mathrm{~cm}$ & $70 \mathrm{~cm}$ & $87 \mathrm{~cm}$ & $110 \mathrm{~cm}$ \\
\cline { 2 - 6 } Crest & -7.7962 & -7.7797 & -7.7842 & -7.7922 & -7.7614 \\
& 6.6625 & 6.5526 & 6.3565 & 6.3257 & 6.0618 \\
\multirow{2}{*}{ Bottom } & -2.3074 & -2.2922 & -2.2831 & -2.2840 & -2.0491 \\
& 2.0120 & 1.9810 & 1.9720 & 1.9756 & 1.8306 \\
\multirow{2}{*}{ Foundation } & -1.7683 & -1.7640 & -1.7620 & -1.7598 & -1.8721 \\
& 2.0278 & 2.0276 & 2.0265 & 2.0253 & 2.2855 \\
\hline \multirow{2}{*}{$\mathrm{a}_{\text {crest }} / \mathrm{a}_{\text {bottom }}$} & 3.3788 & 3.3940 & 3.4095 & 3.7878 \\
$\mathrm{a}_{\text {crest }} / \mathrm{a}_{\text {foundation }}$ & 3.8446 & 3.8370 & 3.8412 & 3.4117 \\
\hline
\end{tabular}

Table 11. The maximum horizontal accelerations and peak acceleration amplification coefficients for friction contact and empty reservoir condition in Case 1

\begin{tabular}{cccccc}
\hline \multirow{2}{*}{$\begin{array}{c}\text { Slab } \\
\text { thickness }\end{array}$} & $30 \mathrm{~cm}$ & $58 \mathrm{~cm}$ & $70 \mathrm{~cm}$ & $87 \mathrm{~cm}$ & $110 \mathrm{~cm}$ \\
\cline { 2 - 6 } Crest & -5.8545 & -5.5189 & -5.4876 & -5.5065 & -5.4993 \\
& 6.3866 & 5.7791 & 5.7557 & 5.7584 & 5.7287 \\
\multirow{2}{*}{ Bottom } & -4.2572 & -2.6067 & -2.6185 & -2.6198 & -2.6236 \\
& 3.2763 & 2.3882 & 2.3959 & 2.4066 & 2.4098 \\
\multirow{2}{*}{ Foundation } & -2.2360 & -1.7446 & -1.7435 & -1.7425 & -1.7417 \\
& 3.0092 & 2.3469 & 2.3469 & 2.3462 & 2.3461 \\
\hline \multirow{2}{*}{$\mathrm{a}_{\text {crest }} / \mathrm{a}_{\text {bottom }}$} & 1.5002 & 2.2170 & 2.1981 & \\
$\mathrm{a}_{\text {crest }} / \mathrm{a}_{\text {foundation }}$ & 2.1224 & 2.4624 & 2.4524 & 2.1980 & 2.1835 \\
\hline
\end{tabular}

Table 12. The maximum horizontal accelerations and peak acceleration amplification coefficients for friction contact and empty reservoir condition in Case 2

\begin{tabular}{cccccc}
\hline \multirow{2}{*}{$\begin{array}{c}\text { Slab } \\
\text { thickness }\end{array}$} & $30 \mathrm{~cm}$ & $58 \mathrm{~cm}$ & $70 \mathrm{~cm}$ & $87 \mathrm{~cm}$ & $110 \mathrm{~cm}$ \\
\cline { 2 - 6 } Crest & -6.7806 & -6.7797 & -6.7747 & -6.4199 & -6.4093 \\
& 6.8807 & 6.7760 & 6.7676 & 6.7114 & 6.5216 \\
\multirow{2}{*}{ Bottom } & -2.2897 & -2.2896 & -2.2896 & -2.2895 & -2.2896 \\
& 5.5638 & 5.5068 & 5.4087 & 5.3641 & 5.2050 \\
\multirow{2}{*}{ Foundation } & -1.7558 & -1.7550 & -1.6745 & -1.6213 & -1.6167 \\
& 2.2625 & 2.1819 & 2.1920 & 2.1881 & 2.1908 \\
\hline \multirow{2}{*}{$\mathrm{a}_{\text {crest }} / \mathrm{a}_{\text {bottom }}$} & 1.2367 & 1.2312 & 1.2526 & \\
$\mathrm{a}_{\text {crest }} / \mathrm{a}_{\text {foundation }}$ & 3.0412 & 3.1073 & 3.0906 & 1.2512 & 1.2529 \\
\hline
\end{tabular}


Table 13. The maximum horizontal accelerations and peak acceleration amplification coefficients for friction contact and full reservoir condition in Case 2

\begin{tabular}{cccccc}
\hline \multirow{2}{*}{$\begin{array}{c}\text { Slab } \\
\text { thickness }\end{array}$} & $30 \mathrm{~cm}$ & $58 \mathrm{~cm}$ & $70 \mathrm{~cm}$ & $87 \mathrm{~cm}$ & $110 \mathrm{~cm}$ \\
\cline { 2 - 6 } Crest & -5.5251 & -5.2149 & -5.2142 & -5.1592 & -5.0641 \\
& 7.5464 & 7.5163 & 7.5244 & 7.5328 & 7.5214 \\
\multirow{2}{*}{ Bottom } & -2.4724 & -2.3476 & -2.3449 & -2.3497 & -2.2130 \\
& 5.2221 & 5.1171 & 5.0078 & 4.2109 & 4.1803 \\
Foundation & -2.3665 & -2.1779 & -2.1754 & -2.1741 & -1.8506 \\
& 3.3355 & 2.9473 & 2.9285 & 2.1931 & 2.1003 \\
\hline \multirow{2}{*}{$\mathrm{a}_{\text {crest }} / \mathrm{a}_{\text {bottom }}$} & 1.4450 & 1.4689 & 1.5026 & \\
$\mathrm{a}_{\text {crest }} / \mathrm{a}_{\text {foundation }}$ & 2.2624 & 2.5503 & 2.5694 & 1.7889 & 1.7993 \\
\hline
\end{tabular}

Table 14. The maximum horizontal accelerations and peak acceleration amplification coefficients for friction contact and empty reservoir condition factors in Case 3

\begin{tabular}{cccccc}
\hline \multirow{2}{*}{$\begin{array}{c}\text { Slab } \\
\text { thickness }\end{array}$} & $30 \mathrm{~cm}$ & $58 \mathrm{~cm}$ & $70 \mathrm{~cm}$ & $87 \mathrm{~cm}$ & $110 \mathrm{~cm}$ \\
\cline { 2 - 6 } Crest & -6.4941 & -6.4980 & -6.4131 & -6.4102 & -6.3987 \\
& 7.1962 & 7.0199 & 6.5311 & 6.5337 & 6.5413 \\
\multirow{2}{*}{ Bottom } & -2.2902 & -2.4639 & -2.2899 & -2.2899 & -2.2901 \\
& 4.7713 & 5.2716 & 5.3464 & 5.4538 & 5.5542 \\
\multirow{2}{*}{ Foundation } & -1.6310 & -1.6358 & -1.6314 & -1.6310 & -1.6336 \\
& 2.2895 & 2.2369 & 2.1906 & 2.1908 & 2.1903 \\
\hline \multirow{2}{*}{$\mathrm{a}_{\text {crest }} / \mathrm{a}_{\text {bottom }}$} & 1.5082 & 1.3317 & 1.2216 & \\
$\mathrm{a}_{\text {crest }} / \mathrm{a}_{\text {foundation }}$ & 3.1431 & 3.1382 & 2.9815 & 1.1980 & 1.1777 \\
\hline
\end{tabular}

Table 15. The maximum horizontal accelerations and peak acceleration amplification coefficients for friction contact and full reservoir condition in Case 3

\begin{tabular}{cccccc}
\hline \multirow{2}{*}{$\begin{array}{c}\text { Slab } \\
\text { thickness }\end{array}$} & $30 \mathrm{~cm}$ & $58 \mathrm{~cm}$ & $70 \mathrm{~cm}$ & $87 \mathrm{~cm}$ & $110 \mathrm{~cm}$ \\
\cline { 2 - 6 } & -4.9891 & -4.8885 & -4.7749 & -4.7802 & -4.7118 \\
Crest & 7.9290 & 7.8085 & 7.8127 & 7.7910 & 7.7638 \\
& -2.4467 & -2.3350 & -2.2814 & -2.2493 & -2.2440 \\
\multirow{2}{*}{ Bottom } & 4.4648 & 4.4502 & 4.4505 & 4.3076 & 4.2128 \\
& -1.8753 & -1.8570 & -1.8747 & -1.8409 & -1.8697 \\
Foundation & 2.5916 & 2.4809 & 2.3693 & 2.1535 & 2.0696 \\
\hline \multirow{2}{*}{$\mathrm{a}_{\text {crest }} / \mathrm{a}_{\text {bottom }}$} & 1.7759 & 1.7546 & 1.7555 & \\
$\mathrm{a}_{\text {crest }} / \mathrm{a}_{\text {foundation }}$ & 3.0595 & 3.1475 & 3.2975 & 1.8086 & 1.8429 \\
\hline
\end{tabular}




\section{- Crest - Bottom - Foundation}

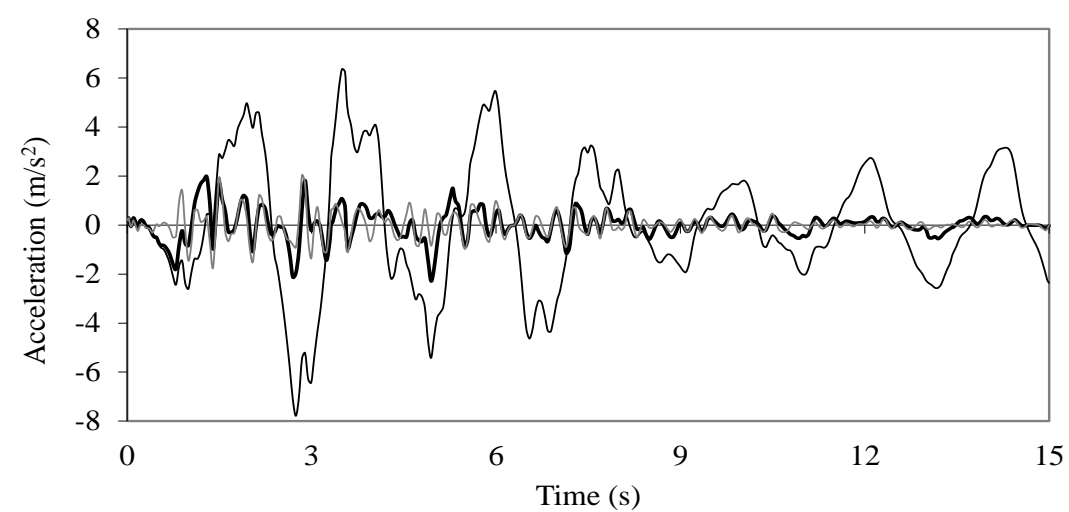

Fig. 17. The horizontal accelerations for friction contact and empty reservoir condition in Case 1

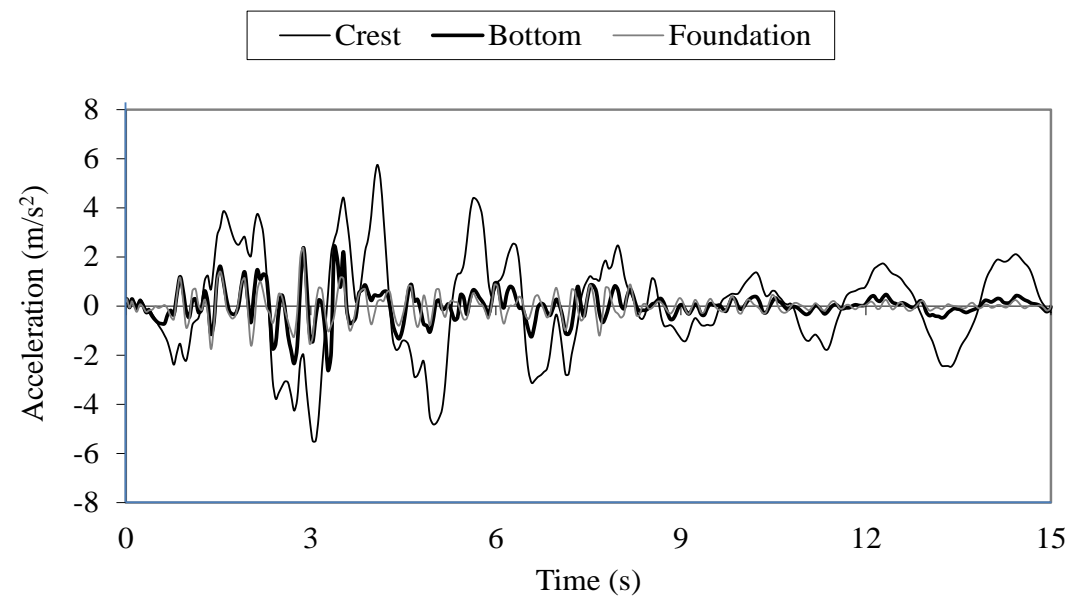

Fig. 18. The horizontal accelerations for friction contact and full reservoir condition in Case 1

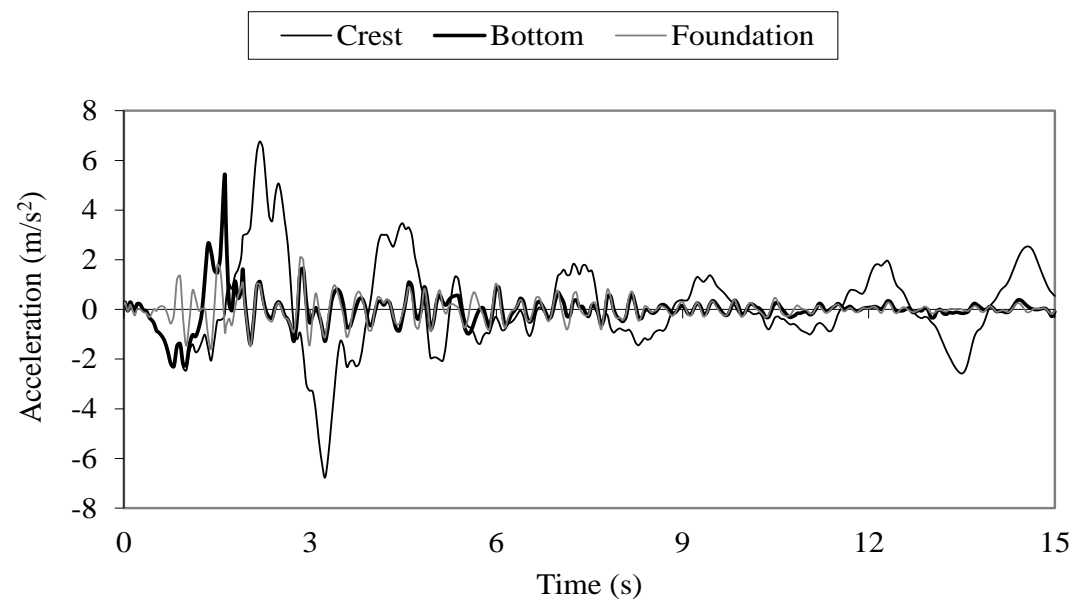

Fig. 19. The horizontal accelerations for friction contact and empty reservoir condition in Case 2 


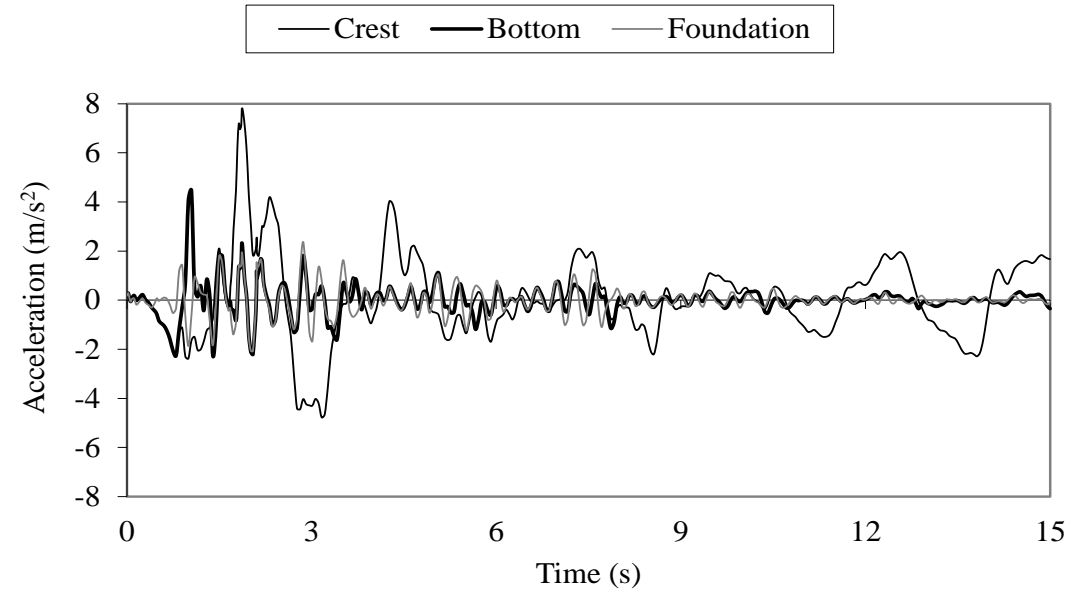

Fig. 20. The horizontal accelerations for friction contact and full reservoir condition in Case 2

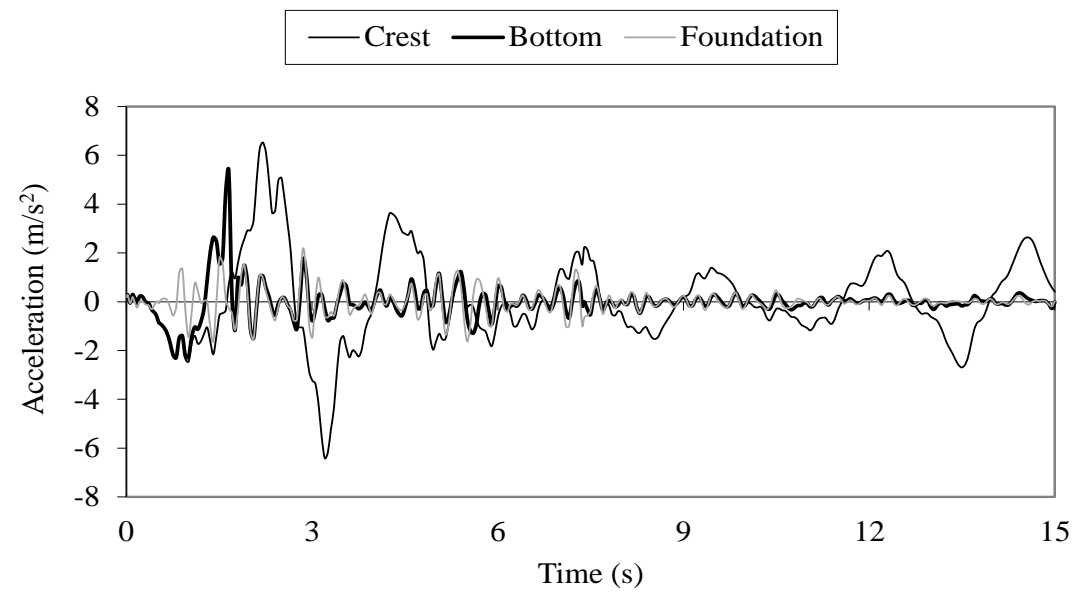

Fig. 21. The horizontal accelerations for friction contact and empty reservoir condition in Case 3

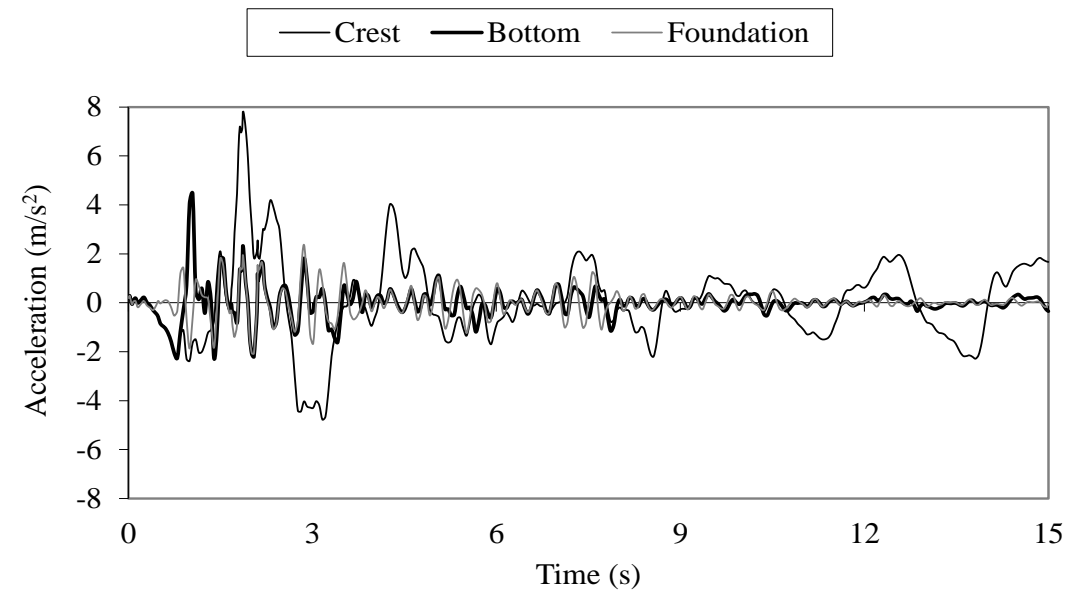

Fig. 22. The horizontal accelerations for friction contact and full reservoir condition in Case 3 
As compared the CFR dam models including welded and friction contact, the horizontal accelerations of the dam including friction contact in the joints have a less and expanded change during earthquake.

The maximum horizontal accelerations occurred in the crest decrease as the concrete slab thickness increases. As compared the horizontal accelerations in the bottom of the dam and the foundation, those in the bottom of the dam are higher than those in the foundation in each reservoir condition. The maximum accelerations occur in Case 3 for empty reservoir condition and nevertheless the accelerations decrease with the increase of the concrete slab thickness. It should be clarified that the horizontal accelerations in the crest, bottom and foundation of the dam have almost no change for different slab thicknesses.

The peak acceleration amplification coefficients increase with the increase of the concrete slab thickness if those are calculated considering the accelerations in the bottom of the dam. Nevertheless, those decrease only in Case 2 for empty reservoir condition. Besides, while the peak acceleration amplification coefficients calculated according to the accelerations in the foundation decrease for empty reservoir condition; those increase for full reservoir condition. The increase of the peak acceleration amplification coefficients in Case 1 for empty reservoir condition and the bottom slab thickness of $110 \mathrm{~cm}$ is based on the decrease of the accelerations in the bottom of the dam. But, the decrease of those according to the acceleration of the foundation the dam is resulted from the increase of the accelerations in the foundation of the dam. In addition to this, while the horizontal accelerations in the bottom and foundation of the dam increase in Case 1 for full reservoir condition and the bottom slab thickness of $30 \mathrm{~cm}$, peak acceleration amplification coefficients clearly decrease.

The peak acceleration amplification coefficients are obtained lower than 2 in Cases 2 and 3 for each reservoir condition. Nevertheless, those increases in Case 1 and furthermore obtained accelerations exceed 3 for empty reservoir conditions. The peak acceleration amplification coefficients obtained using the accelerations in the foundation of the dam are higher than those obtained using the accelerations in the bottom of the dam because the horizontal accelerations in the bottom of the dam are higher than those in the foundation of the dam.

According to comparison in Case 1 for each reservoir condition, the peak acceleration amplification coefficients obtained from the CFR dam including friction are higher than those obtained from the CFR dam including welded contact in the joints. However, in Cases 2 and 3, while the peak acceleration amplification coefficients obtained using the accelerations in the foundation of the dam including friction in the joints are higher than those obtained from the dam including welded contact in the joints, the peak acceleration amplification coefficients are lower than those obtained in the bottom of the dam including friction in the joints.

\section{Conclusions}

The change of accelerations in a typical CFR dam to deconvolved ground motion is presented. The Drucker-Prager model is used for concrete slab and multi-linear kinematic hardening model is utilized for rockfill in the materially non-linear analysis. The selected dam considers welded and friction contacts in the structural connections. Contact elements based on the Coulomb's friction law provide friction between the surfaces. Hydrodynamic pressure on the upstream face is considered using the fluid finite elements based on the Lagrangian approach. This study presents accelerations during earthquake and peak acceleration amplification coefficients obtained from the dam.

According to this study, the horizontal accelerations and the peak acceleration amplification coefficients increase in the crest when the rockfill is linear and welded contact existed in the joints. However, the maximum horizontal accelerations and peak acceleration amplification coefficients decrease in the crest when the rockfill is materially non-linear. When the 
rockfill is linear for each reservoir condition, the peak acceleration amplification coefficients for friction contact are higher than those for welded contact. When the rockfill is non-linear the peak acceleration amplification coefficients obtained from the accelerations in the foundation of the dam for friction contact are higher than those for welded contact. In addition to this, the peak acceleration amplification coefficients obtained from the accelerations in the foundation of the dam are lower than those obtained from the bottom of the dam for friction contact.

\section{References}

[1] Guros FB, Thiers GR, Wathen TR, Buckles CE. Seismic design of concrete-faced rockfill dams. Proceedings of the 8th World Conference on Earthquake Engineering, San Francisco, Prentice-Hall, Englewood Cliffs, NJ, 3: 317-323, 1984.

[2] Arrau L, Ibarra I, Noguera G (1985) Performance of Cogoti dam under seismic loading, In: Concrete Face Rockfill Dams-Design, Construction and Performance. ASCE, New York 1-14.

[3] Bureau G, Volpe RL, Roth W, Udaka T. Seismic analysis of concrete face rockfill dams, Proceedings of the Symposium on Concrete Face Rockfill Dams-Design. Construction and Performance, Detroit, Michigan, ASCE 479-508, 1985, New York.

[4] Uddin N, Gazetas G (1995) Dynamic response of concrete-faced rockfill dams to strong seismic excitation. Journal of Geotechnical Engineering, ASCE 121(2): 185-197.

[5] Bayraktar A, Kartal ME, Adanur S, (2011) The effect of concrete slab-rockfill interface behavior on the earthquake performance of a CFR dam. International Journal of Non-Linear Mechanics 46(1): 35-46.

[6] Kartal ME, Bayraktar A (2015) Non-Linear Response of the Rockfill in a Concrete Faced Rockfill Dam under Seismic Excitation. Mathematical and Computer Modelling of Dynamical Systems 21(1): 77-101.

[7] Rollins KM, Evans MD, Diehl NB, Daily III WD, (1998) Shear modulus and damping relationships for gravels. Journal of Geotechnical and Geoenvironmental Engineering 124(5): 396405.

[8] Wilson EL, Khalvati M (1983) Finite elements for the dynamic analysis of fluid-solid systems. International Journal for Numerical Methods in Engineering 19(11): 1657-1668.

[9] Calayır Y. Dynamic analysis of concrete gravity dams using the Eulerian and the Lagrangian Approaches. PhD. Thesis, Karadeniz Technical University, 1994

[10] Zienkiewicz OC, Taylor RL. The Finite Element Method, McGraw-Hill, 1989.

[11] Bathe KJ. Finite Element Procedures in Engineering Analysis. Prentice-Hall, Englewood Cliffs, NJ, 1996.

[12] Clough RW, Penzien J. Dynamics of Structures. Second ed., McGraw-Hill, Singapore, 1993.

[13] Akkas N, Akay HU, Yilmaz C (1979) Applicability of general-purpose finite element programs in solid-fluid interaction problems. Computers \& Structures 10(5): 773-783.

[14] DSI. General Directorate of State Hydraulic Works. The XXII. Regional Directorate, Trabzon, 2017.

[15] Haeri SM, Karimi M. Three dimensional response of concrete faced rockfill dams to strong earthquakes considering dam-foundation interaction and spatial variable ground motion. First European Conference on Earthquake Engineering and Seismology, Geneva, Switzerland, ID 1406, 2006.

[16] Varadarajan A, Sharma KG, Abbas SM, Dhawan AK (2006) Constitutive model for rockfill materials and determination of material constants. International Journal of Geomechanics, ASCE 6(4): 226-237.

[17] TS 500. Requirements for Design and Construction of Reinforced Concrete Structures, 2000.

[18] ANSYS, Swanson Analysis Systems Inc, Houston PA, USA, 2016.

[19] Schnabel PB, Lysmer J, Seed HB. SHAKE: A computer program for earthquake response analysis of horizontally layered sites. Report No.EERC-72/12, Earthquake Engineering Research Centre, University of California, Berkeley, 1972.

[20] Qian C. Recent Development of CFRD in China. Proceedings of Symposium on 20 years for Chinese CFRD Construction, Yichang, China, 8$15,2005$. 
[21] Seed HB. The Influence of local soil conditions on earthquake damage. Proceedings, soil dynamics specialty session, Seventh international conference of soil mechanics and foundation engineering, Mexico, 1969.

[22] Kramer SL. Geotechnical Earthquake Engineering, Prentice-Hall Inc., First edition, New Jersey, 1996.

[23] PEER. Pacific Earthquake Engineering Research Centre, http://peer.berkeley.edu/smcat, 2016.
[24] Idriss IM, Sun JI. SHAKE91: A computer program for conducting equivalent linear seismic response analyses of horizontally layered soil deposits. Center of Geotechnical Modeling Department of Civil \& Environmental Engineering. University of California Davis, California, 1992.

[25] Cascone E, Rampello S (2003) Decoupled Seismic Analysis of an Earth Dam. Soil Dynamics and Earthquake Engineering 23(5): 349-365. 